\title{
Endometriosis: Pathogenesis, diagnosis, therapy and association with cancer (Review)
}

\author{
ALFONSO BALDI ${ }^{1,2}$, MARA CAMPIONI ${ }^{1,2}$ and PIETRO G. SIGNORILE $^{1}$ \\ ${ }^{1}$ Fondazione Italiana Endometriosi, Rome; ${ }^{2}$ Department of Biochemistry, \\ Section of Pathology, Second University of Naples, Naples, Italy \\ Received January 21, 2008; Accepted February 11, 2008
}

\begin{abstract}
Endometriosis is a painful reproductive and immunological disease afflicting about $7-10 \%$ of women worldwide. It is one of the most frequent benign gynaecological diseases; however, little is known about the pathogenetic processes leading to the development and maintenance of this disease and the currently available therapeutic strategies are unsatisfactory. The goal of this article is to review the most recent advancements in the pathogenesis, diagnosis and therapy of this disease. The risk for cancer among women with endometriosis will be analyzed in light of the most recent epidemiological and functional studies focused on this disease.
\end{abstract}

\section{Contents}

1. Introduction

2. Theories of pathogenesis

3. Diagnosis and therapy

4. Endometriosis and the risk of cancer

5. Conclusions

\section{Introduction}

Endometriosis is a gynaecological disease defined by the histological presence of endometrial glands and stroma outside the uterine cavity, most commonly implanted over visceral and peritoneal surfaces within the female pelvis, but rarely also in the pericardium, pleura, and even brain (1). Although the exact prevalence of endometriosis in the population is not clear, the prevalence in the general female population is 6-10\%; in women with pain, infertility or both, the frequency increases to $35-60 \%$ (2). Endometriosis is usually associated with

Correspondence to: Professor Alfonso Baldi, Department of Biochemistry, Section of Pathology, Second University of Naples, Via L. Armanni 5, I-80138 Naples, Italy

E-mail: alfonsobaldi@tiscali.it

Key words: endometriosis, pathogenesis, diagnosis, therapy, cancer infertility and pelvic pain such as chronic dysmenorrhea, intermenstrual abdominal and pelvic pain, back pain, dysuria, dyschezia and dyspareunia (1). This disease was first identified and described in 1860 by the Austrian pathologist von Rokitansky (3), but despite the fact that it is quite common among women, it is frequently misdiagnosed, the pathogenesis is not completely clear and the diagnostic and therapeutic strategies are still not adequate. In this report, the most recent findings on the pathogenesis, the diagnosis and therapy of this disease, as well as the associated risk of developing a malignancy, are reviewed.

\section{Theories of pathogenesis}

Although there are several theories the definitive cause of endometriosis is still unclear. In Table I the most common theories on the pathogenesis of this disease are summarized.

One widely accepted mechanism for the development of peritoneal endometriotic lesions is the adhesion and growth of endometrial fragments deposited into the peritoneal cavity via retrograde menstruation (4). The retrograde menstruation/ transplantation theory is supported by the fact that the women with endometriosis have higher volumes of refluxed menstrual blood and endometrial-tissue fragments than healthy women (5). Moreover, endometriosis affects young women with primary amenorrhoea and outlet obstruction to menstrual flow (6), and it can be induced in baboons by ligation of the cervix (7). However, this theory fails to explain the presence of endometriosis in such remote areas as the lungs, skin, lymph nodes, breasts; nor does this theory account for the few described cases of male endometriosis (8).

The coelomic metaplasia theory claims that formation of endometriomas in the ovary or rectovaginal endometriosis is caused by metaplasia of the coelomic epithelium, perhaps induced by environmental factors (9-11). This theory would explain why most women have some degree of retrograde menstruation but only a small percentage have endometriosis, and the presence of the disease in absence of menses.

Anatomic abnormalities are also considered a possible precursor of endometriosis. Vercellini et al concluded that the depth and volume of the cul-de-sac (Pouch of Douglas), differs in patients with endometriosis with or without deep lesions as compared to women with a healthy pelvis (12). 
Table I. Theories on the pathogenesis of endometriosis.

Retrograde menstruation/transplantation

Coelomic metaplasia

Anatomic abnormalities

Genetic basis

Enviromental basis

Altered cellular immunity
Table II. Drugs used for the treatment of endometriosis.

\begin{tabular}{ll}
\hline Androgens & Danazol \\
GnRH agonists & $\begin{array}{l}\text { Leuprolide, Leuprolide depot, } \\
\text { Burserelin, Goserelin, Nafarelin }\end{array}$ \\
Progestagens & Gestrinone, Medroxyprogesterone \\
Oral contraceptives & Combination of oestrogen/progestagen
\end{tabular}

of diagnosis is still the direct visualization of the lesions by invasive surgery through laparoscopy or laparotomy $(34,35)$.

The therapeutic strategies have two principal aims: relief of pain, amelioration of infertility, or both. Drugs that have been classically used to treat endometriosis are summarized in Table II. Research in the field of endometriosis in the last few years has allowed a better understanding of the biology of pain at cellular level. In particular, it has been proposed that release of inflammatory agents, such as prostaglandins, bradykinin, interleukins, norepiphrenine and adenosine, at the implant sites is an important mediator of hyperalgesia (36-38). Moreover, the specific type of innervation of the endometriotic lesions seems to play a role in the phenomenon of hyperlagesia (39-41). It is likely that new therapies will be established based on many of the molecular targets summarised above. To date, the principal agents that have been used to treat endometriosis are drugs able to suppress ovarian function and limit growth and activity of endometriosis and pain associated with the disease, including androgens, progestagens, GnRH agonists, and contraceptive steroids (42-46).

It is well known that medical therapies for pain are, in general, not useful for infertility. Surgery is commonly used to treat infertility related to endometriosis, even if the analysis of the non-randomised trials did not completely support this (47-49). Moreover, it must be considered that surgery could remove some healthy ovarian cortex with follicles, thus resulting in decreased ovarian response during reproduction treatment and in a potential increased risk of earlier menopause $(50,51)$. Therefore, the risks and benefits associated with surgical treatment of patients with endometriosis must be carefully weighed. Nevertheless, it must be pointed out that assisted reproduction by controlled ovarian hyperstimulation and intrauterine insemination, or in vitro fertilisation are beneficial (52-54).

\section{Endometriosis and the risk of cancer}

Epidemiological studies have shown that women with endometriosis have an increased risk of different types of malignancies, especially ovarian cancer and non-Hodgkin's lymphoma (55-57). Nevertheless, recent reports show also an association between endometriosis, dysplastic nevi, and melanoma, and breast cancer (58-60).

Concerning ovarian cancer, several studies have indicated endometriosis as a risk factor and various histological and

\section{Endometriosis continues to remain a significantly under- diagnosed and under-treated disease (1). Despite recent progress in the understanding of this disease, the mainstay \\ 3. Diagnosis and therapy}


molecular genetic studies have even indicated that endometriosis may transform into cancer or that it could be considered a precursor of cancer (61-65). In particular, by microsatellite analysis, it has been recently demonstrated that loss of heterozygosity on p16(Ink4), GALT, and p53, as well as on APOA2, a region frequently lost in ovarian cancer, occurs in endometriosis, even in stage II of the disease. The occurrence of such genomic alterations may represent, therefore, important events in the development of endometriosis. Moreover, the 9p21 locus where p16 is mapped, may contain a gene associated with the pathogenesis of the disease, and its loss may be a prognostic marker of the disease (66).

Although many of the risk factors associated with both diseases are similar, including earlier menarche, more regular periods, shorter cycle length and lower parity, endometriosis itself may be considered a risk factor for ovarian cancer. In a recent study it has been reported that, after adjusting for age, number of pregnancies, family history of ovarian cancer, race, oral contraceptive use, tubal ligation, hysterectomy and breast feeding, women with ovarian cancer were 1.7-fold more likely to have a history of endometriosis than controls (67). However, despite the histological and epidemiological evidence linking endometriosis and ovarian cancer, it is still not clear if endometriosis is a real precursor of ovarian cancer, or whether there is an indirect link involving common environmental, immunological, hormonal or genetic factors (64). It has been clearly demonstrated that activation of a mutated K-ras gene is a fundamental step in the genesis and progression of ovarian cancer $(68,69)$. Moreover, it has been proposed that aberrant transcriptional regulation of the H-ras proto-oncogene is caused by $\mathrm{p} 53$ protein alterations: in fact, the human c-H-ras1 gene contains within the first intron a p53 element, which functions as a transcriptional enhancer (70). Based on these observation, Dinulescu et al have engineered a new transgenic mouse both as model of endometriosis and as a model of endometrioid ovarian carcinoma (71). Briefly, by taking advantage of the Cre recombinase technology, Dinulescu et al first generated mice with a mutationally activated K-ras gene: these mice developed spontaneously benign endometrioid lesions on the ovarian epithelium in all mice and peritoneal endometriosis in about half of the cases. In the second phase, these mice were engineered to lack the expression of Pten. This second mutation caused the insurgence of invasive endometrioid carcinomas of the ovary. This model represents the first mouse model of spontaneous human endometriosis and strongly suggests that the endometriotic lesions are initiated by endometrium refluxed through the fallopian tubes into the peritoneal cavity.

In conclusion, further epidemiological and genetic studies are required for delineation of the risk of several malignancies and in particular of ovarian cancer in women with endometriosis. Nevertheless, appropriate physical screening, laboratory and imaging testing are recommended for early detection of malignant disorders in women with endometriosis.

\section{Conclusions}

Endometriosis still remains an underdiagnosed and debilitating disorder affecting a large cohort of women. It is hoped that biomedical research in the next few years will define effective non-invasive methods to diagnose the disorder and new therapies combined with established medical and surgical therapies to offer relief from pain, prevent progression of the disease, and improve fertility.

\section{Acknowledgements}

This work was supported by a grant from Fondazione Italiana Endometriosi.

\section{References}

1. Giudice LC and Kao LC: Endometriosis. Lancet 364: 1789-1799, 2004.

2. Houston DE: Evidence for the risk of pelvic endometriosis by age, race, and socioeconomic status. Epidemiol Rev 6: 167-191, 1984.

3. Von Rokitansky C: Ueber uterusdrusen-neubildung in uterus and ovarilsarcomen. Z Ges Aertze Wein 37: 577-593, 1860.

4. Sampson JA: Peritoneal endometriosis due to menstrual dissemination of endometrial tissue into the peritoneal cavity. Am J Obstet Gynecol 14: 442-469, 1927

5. Halme JA, Hammond MG, Hulka JF, Raj S and Talbert LM: Retrograde menstruation in healthy women and in patients with endometriosis. Obstet Gynecol 64: 333-337, 1984.

6. Nunley WC Jr and Kitchin JD: Congenital atresia of the uterine cervix with pelvic endometriosis. Arch Surg 115: 757-758, 1980.

7. De Hooge TM: Clinical relevance of the baboon as a model for the study of endometriosis. Fertil Steril 68: 613-625, 1997.

8. Martin JD and Hauck AE: Endometriosis in the male. Am Surg 51: 426-430, 1985.

9. Nap AW, Groothuis PG, Demir AY, Evers JL and Dunselman GA: Pathogenesis of endometriosis. Bet Pract Res Clin Obstet Gynaecol 18: 233-244, 2004.

10. Brosens I: Endometriosis and the outcome of in vitro fertilization. Fertil Steril 81: 1198-1200, 2004.

11. Nisolle M and Donnez J: Peritoneal endometriosis, ovarian endometriosis, and adenomyotic nodules of the rectovaginal septum are three different entities. Fertil Steril 68: 585-595, 1997.

12. Vercellini P, Aimi G, Panazza S, Vicentini S, Pisacreta A and Crosignani PG: Deep endometriosis conundrum, evidence in favour of a peritoneal origin. Fertil Steril 73: 1043-1046, 2000.

13. Simpson JL, Elias S, Malinak LR and Buttram VC: Heritable aspects of endometriosis, I: genetic studies. Am J Obstet Gynecol 137: 327-331, 1980

14. Kennedy S, Bennet S and Weeks DE: Afected sib-pair analysis in endometriosis. Human Reprod Update 7: 411-418, 2001.

15. Kennedy SH: Genetics of endometriosis, a review of the positional cloning approaches. Semin Reprod Med 21: 111118,2003

16. Bischoff FZ, Marquez-Do DD, Carson SA, Buster JE and Simpson JL: NAT2 and GST M1 DNA polymorphism, increased GSTM1 (active) genotype in endometriosis. Fertil Steril 77: S17, 2002.

17. Nakago S, Hadfield RM, Zondervan KT, et al: Association between endometriosis and $\mathrm{N}$-acetyl transferase polymorphisms in a UK population. Mol Hum Reprod 7: 1079-1082, 2001.

18. Baxter SW, Thomas EJ and Campbell IG: GSTM1 null polymorphism and susceptibility to endometriosis and ovarian cancer. Carcinogenesis 22: 63-65, 2001.

19. Zondervan KT, Cadon LR and Kennedy S: What makes a good case control study? Design issues for complex traits such as endometriosis. Hum Reprod 17: 1415-1423, 2002.

20. Arvanitis DA, Goumenou AG, Matalliotakis IM, Koumantakis EE and Spandidos DA: Low-penetrance genes are associated with increased susceptibility to endometriosis. Fertil Steril 76: 12021206, 2001.

21. Arvanitis DA, Koumantakis GE, Goumenou AG, Matalliotakis IM, Koumantakis EE and Spandidos DA: CYP1A1, CYP19, and GSTM1 polymorphisms increase the risk of endometriosis. Fertil Steril 79 (Suppl 1): 702-709, 2003.

22. Grummer R: Animal models in endometriosis research. Human Reprod Update 12: 641-649, 2006.

23. Fanton JW and Golden JG: Radiation-induced endometriosis in Maccaca mulatta. Radiat Res 126: 141-146, 1991. 
24. Rier SE, Martin DC, Bowman RE, et al: Endometriosis in rhesus monkeys (Maccaca mulatta) following chronic exposure to 2,3,7,8 tetrachlorodibenzo-p-dioxin. Fundam Appl Toxicol 21: 431-441, 1993.

25. Sharpe RM and Frank S: Enviroment, lifestyle and infertility, an intergenerational issue. Nat Cell Biol 4 (Suppl): S33-S40, 2002.

26. Leibovic DI, Mueller MD and Taylor RN: Immunobiology of endometriosis. Fertil Steril 75: 1-10, 2001.

27. Sharpe-Timms KL, Zimmer RL, Ricke EA, Piva M and Horowitz GM: Endometriotic haptoglobin binds to peritoneal macrophages and alters their function in women with endometriosis. Fertil Steril 78: 810-819, 2002.

28. Santanam M, Murphy AA and Parthasarathy S: Macrophages, oxidation, and endometriosis. Ann NY Acad Sci 955: 183-200, 2001.

29. Nothnick WB: Treating endometriosis as an autoimmune disease. Fertil Steril 76: 223-240, 2001.

30. Badawy SZ, Cuenca V, Stitzel A and Tice D: Immune rosettes of $\mathrm{T}$ and $\mathrm{B}$ lymphocytes in infertile women with endometriosis. J Reprod Med 32: 194-197, 1987.

31. Gleicher N, El-Roeiy A, Confino E and Friberg J: Is endometriosis an autoimmune disease? Obstet Gynecol 70: 115-122, 1987.

32. Grossinkinsky CM and Halme J: Endometriosis: the host response. Baillieres Clin Obstet Gynaecol 7: 701-713, 1993.

33. Sinaii N, Cleary SD, Ballweg ML, Nieman LK and Stratton P: High rates of autoimmune and endocrine disorders, fibromyalgia, chronic fatigue syndrome, and atopic diseases among women with endometriosis: a survey analysis. Hum Reprod 17: 2715-2724, 2002.

34. Lessey BA: Medical management of endometriosis and infertility. Fertil Steril 73: 1089-1096, 2000.

35. Valle RF and Sciarra JJ: Endometriosis: treatment strategies. Ann NY Acad Sci 955: 281-292, 2001.

36. De Leon FD, Vijayakumar R, Rao CV and Yussam M: Prostaglandin F2 alpha and E2 release by peritoneum with and without endometriosis. Int J Fertil 33: 48-51, 1988.

37. Lessey BA, Castelbaum AJ, Sawin SW, Buck CA, Schinnar R, Bilker W and Strom BL: Aberrant integrin expression in the endometrium of women withy endometriosis. J Clin Endocrinol Metab 79: 643-649, 1994.

38. Bergqvist A, Bruse C, Carlberg $\mathrm{M}$ and Carlstrom $\mathrm{K}$ : Interleukin 1 beta, interleukin- 6 , and tumour necrosis factor-alpha in nedometriotic tissue and in endometrium. Fertil Steril 75: 489-495, 2001.

39. Anaf V, Simon P, Nakadi IEI, Fayt I, Simonart T, Buxant F and Noel JC: Hyperalgesia, nerve infiltration and nerve growth factor expression in deep adenomyotic nodules, peritoneal and ovarian endometriosis. Hum Reprod 17: 1895-1900, 2002.

40. Togushige N, Markham R, Russell P and Fraser IS: High density of small nerve fibres in the functional layer of the endometrium in women with endometriosis. Hum Reprod 21: 782-787, 2006.

41. Tokushige N, Markham R, Russel P and Fraser IS: Nerve fibers in peritoneal endometriosis. Hum Reprod 21: 3001-3007, 2006.

42. Rice VM: Conventional medical therapies for endometriosis. Ann NY Acad Sci 955: 343-359, 2001.

43. Gibbons WE: Management of endometriosis in fertility patients. Fertil Steril 81: 1204-1205, 2004.

44. Deveroey P: Ovarian stimulation regimens in women with endometriosis. J Gynecol Obstet Biol Reprod (Paris) 32: S42-S44, 2004.

45. Telimaa S, Puolakka J, Ronnberg L and Kaupilla A: Placebocontrolled comparison of danazol and high-dose medroxyprogesterone acetate in the treatment of endometriosis. Gynecol Endocrinol 1: 13-25, 1987

46. Olive DA and Pritts EA: The treatment of endometriosis: a review of the evidence. Ann NY Acad Sci 955: 360-372, 2001.

47. Hughes EG, Dedorkow DM and Collins JA: A quantitative overview of controlled trials in endometriosis-associated infertility. Fertil Steril 59: 963-976, 1993.

48. Marcoux S, Maheux R and Bedrub S: Laparoscopic surgery in infertile women with minimal or mild endometriosis: Canadian Collaborative Group in Endometriosis. N Engl J Med 337: 217-222, 1997.

49. Parazzini F: Ablation of lesions or no treatment in minimal-mild endometriosis in infertile women: a randomized trial. Hum Reprod 14: 1332-1334, 1999

50. Garcia-Velasco JA, Mahutte NG, Corona J, et al: Removal of endometriomas before in vitro fertilization does not improve fertility outcomes: a matched, case-control study. Fertil Steril 81: 1194-1197, 2004.
51. De Boer EJ, den Tomkelaar I, te Velde ER, Burger CW, van Leeuwen FE and OMEGA-project group: Increased risk of early menopausal transition and natural menopause after poor response at first IVF treatment. Hum Reprod 18: 1544-1552, 2003.

52. Fedele L, Bianchi S, Marchini M, Villa L, Brioschi D and Parazzini F: Superovulation with human menopausal gonadotropins in the treatment of infertility associated with minimal or mild endometriosis: a controlled randomized study. Fertil Steril 58: 28-31, 1992.

53. Deaton JL, Gibson M, Balckmer KM, et al: A randomized, controlled trial of clomiphene citrate and intrauterine insemination in couples with unexplained infertility or surgically corrected endometriosis. Fertil Steril 54: 1083-1088, 1990.

54. Tummon IS, Asher LJ, Martin JS and Tulandi T: Randomized controlled trial of superovulation and insemination for infertility associated with minimal or mild endometriosis. Fertil Steril 68: 8-12, 1997

55. Brinton LA, Gridley G, Persson I, Baron J and Bergqvist A: Cancer risk after a hospital discharge diagnosis of endometriosis. Am J Gynecol 176: 572-579, 1997.

56. Olson JE, Cerhan JR, Janney CA, Anderson KE, Vachon CM and Sellers TA: Postmenopasual cancer risk after self-reported endometriosis diagnosis in the Iowa women's health study. Cancer 94: 1612-1618, 2002.

57. Melin A, Sparen P and Bergqvist A: Endometriosis and the risk of cancer with special emphasis on ovarian cancer. Hum Reprod 21: 1237-1242, 2006.

58. Wyshak G, Frisch RE, Albright NL, Albright TE and Schiff I: Reproductive factors and melanoma of the skin among women. Int J Dermatol 28: 527-530, 1989.

59. Hornstein MD, Thomas PP, Sober AJ, Wyshak G, Albright NL and Frisch RE: Association between endometriosis, dysplastic nevi and history of melanoma in women of reproductive age. Hum Reprod 12: 143-145, 1997.

60. Bertelsen L, Mellemkjer L, Frederiksen K, Kyer SK, Brinton LA, Sakoda LC, van Valkengoed I and Olsen JH: Risk for breast cancer among women with endometriosis. Int J Cancer 120: 1372-1375, 2007.

61. Melin A, Sparen P and Berqvist A: The risk of cancer and the role of parity among women with endometriosis. Hum Reprod 22: 3021-3026, 2007

62. Ogawa S, Kaku T, Amada S, Kobayashi H, Hirakawa T, Arioshi K, Kamura T and Nakano H: Ovarian endometriosis associated with ovarian carcinoma: a clinicopathological and immunohistochemical study. Gynecol Oncol 77: 298-304, 2000.

63. Yoshikawa H, Jimbo H, Okada S, Matsumoto K, Onda T, Yasugi T and Taketani Y: Prevalence of endometriosis in ovarian cancer. Gynecol Obstet Invest 50: 11-17, 2000.

64. Varma R, Rollason T, Gupta JK and Maher ER: Endometriosis and the neoplastic process. Reproduction 127: 293-304, 2004.

65. Prowse AH, Manek S, Varma R, Liu J, Godwin AK, Maher ER, Tomlinson IPM and Kennedy SH: Molecular genetic evidence that endometriosis is a precursor of ovarian cancer. Int J Cancer 119: 556-562, 2006

66. Goumenou AG, Arvanitis DA, Matalliotakis IM, Koumantakis EE and Spandidos DA: Microsatellite DNA assays reveal an allelic imbalance in p16(Ink4), GALT, p53, and APOA2 loci in patients with endometriosis. Fertil Steril 75: 160-165, 2001.

67. Ness RB, Grisso JA, Cottreau C, Klapper J, Vergona R, Wheeler JE, Morgan M and Schlesselman JJ: Factors related to inflammation of the ovarian epithelium and risk of ovarian cancer. Epidemiology 11: 111-117, 2000.

68. Mammas IN, Zafiropoulos A and Spandidos DA: Involvement of the ras genes in female genital tract cancer: Int J Oncol 26: 1241-1255, 2005.

69. Dokianakis DN, Varras MN, Papaefthimiou M, Apostolopoulou J, Simiakaki H, Diakomanolis E and Spandidos DA: Ras gene activation in malignant cells of human ovarian carcinoma peritoneal fluids. Clin Exp Metastasis 17: 293-297, 1999.

70. Zachos G and Spandidos DA: Transcriptional regulation of the c-H-ras1 gene by the P53 protein is implicated in the development of human endometrial and ovarian tumours. Oncogene 16: 3013-3017, 1998.

71. Dinulescu DM, Ince TA, Quade BJ, Shafer SA, Crowley D and Jacks T: Role of K-ras and Pten in the development of mouse models in endometriosis and endometrioid ovarian cancer. Nat Med 11: 63-70, 2005. 